\title{
Urinary tract infections, bacterial resistance and immunological status: a cross sectional study in pregnant and non-pregnant women at Mbouda Ad-Lucem Hospital
}

\author{
Loveline M Ndamason, Wiliane JT Marbou, Victor Kuete
}

Department of Biochemistry, Faculty of Science, University of Dschang, Cameroon.

\section{Author emails:}

Loveline Mbutih Ndamason: nloveline@rocketmail.com, Wiliane J.T. Marbou: marboutakougoum@yahoo.fr

\begin{abstract}
Background: Urinary tract infections (UTI) are frequently encountered medical complications of pregnancy.

Objective: This study was aimed at analyzing the bacterial resistance in urogenital tract as well as the immunological profile amongst pregnant and non-pregnant women at Mbouda Ad-Lucem Hospital, Western Region of Cameroon.

Methods: A cross-sectional study was carried out from December 2015 to May 2016 at Mbouda Ad-Lucem hospital on 104 pregnant women and 24 non-pregnant women. The midstream urine from participants was analysed for the presence, isolation and identification of the uro-pathogens, using selective and specific bacterial culture media. An antibiotic susceptibility tests was carried out using disk diffusion method. Blood samples were collected for C-reactive protein (CRP) dosage, CD4 and CD8 lymphocytes count.

Results: Out of 128 participants in this study, a high prevalence of uro-pathogens and resistance strains was observed. The most prevalent urinary tract pathogens were Staphylococcus sp. with $45 \%$ and $38.89 \%$ respectively in pregnant and non-pregnant women. Staphylococcus sp. showed resistance to Amoxicillin (AMO; 55.56\%) and Chloramphenicol (CHL; 100\%) respectively in pregnant and non-pregnant women. Pregnant women had a significantly high average of granulocytes $(p=0.009)$, monocytes $(\mathrm{P}=0.001)$, high ratio of $\mathrm{CD} 4 / \mathrm{CD} 8(\mathrm{p}<0.0001)$ and significantly low CD8 lymphocytes $(\mathrm{p}<0.0001)$ average compared to non-pregnant women.

Conclusion: This study outlines high prevalence of Stapbylococcus sp as the main urinary tract infectious pathogen in women at Mbouda Ad-Lucem hospital. It prevalence was accompanied with resistance to the routine antibiotics treatment, and a pronounced lymphocytosis and monocytosis.
\end{abstract}

Keywords: Antibiotic resistance; bacterial profile; immunological status; Mbouda; multidrug-resistance; pregnancy.

DOI: https://dx.doi.org/10.4314/ahs.v19i1.26

Cite as: Ndamason LM, Marbou WJT, Kuete V. Urinary tract infections, bacterial resistance and immunological status: a cross sectional study in pregnant and non-pregnant women at Mbouda Ad-Lucem Hospital. Afri Health Sci. 2019;19(1). 1525-1535. https:/ / dx.doi.org/ 10.4314/ abs.v19i1.26

\author{
Corresponding author: \\ Victor Kuete, \\ Department of Biochemistry, \\ Faculty of Science, University of Dschang, \\ Cameroon \\ Tel : (237) 6773559 27; P.O. Box 67 Dschang, \\ Cameroon; \\ Email: kuetevictor@yahoo.fr
}

\section{Introduction}

Pregnant women attending ante-natal visit for check-up of their health and that of their foetuses may not necessarily be presenting any symptoms of illness ${ }^{1}$. However, urinary tract infections (UTIs) (mostly bacteriuria, vaginitis, cystitis and pyelonephritis) are frequently encountered medical complications of pregnancy ${ }^{2}$. Although the majority of infections in pregnancy maybe asymptomatic, studies have revealed that they pose high risk of low birth weight, preterm labour, hypertension, maternal

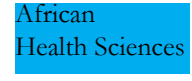

(C) 2019 Ndamason et al. Licensee African Health Sciences. This is an Open Access article distributed under the terms of the Creative commons Attribution License (https://creativecommons.org/licenses/BY/4.0), which permits unrestricted use, distribution, and reproduction in any medium, provided the original work is properly cited. 
anaemia, thrombosis, still birth and abortion ${ }^{2,3}$. There are hormonal, structural and functional alterations of the urinary tract (UT) during pregnancy ${ }^{4}$. Pregnancy influences the immune system of pregnant women. This influence makes pregnant women vulnerable and can promote growth of bacteria due to inadequate immune response. During pregnancy, prophylaxis antibiotherapy may lead to the development of resistance in these bacteria ${ }^{4}$.

Glomerular filtration rate and urinary output increases due to blood-volume expansion ${ }^{5}$. These predisposes the pregnant women to microbial infection. The microbes present may not be pathogenic except in situations where their growth in the UT is excessive or co-presence with other competing microorganisms. Indeed, it has been shown that frequent antenatal visits may increase the exposure of pregnant women to nosocomial microorganisms and thereby nosocomial associated infections ${ }^{6}$.

A limited spectrum of organisms cause UTIs. This include E. coli as the major etiologic agent in UTIs. Proteus mirabilis, Klebsiella sp. Pseudomonas aeruginosa and Enterobacter $s p$. are less frequent causative agents. Enterococci, Gardnerrella vaginalis and U urealyticum are also known agents in UTIs. Gram-positive microorganisms including; Streptococcus, Staphylococcus aureus, Staphylococcus saprophyticus and Staphylococcus haemolyticus have also been pinpointed as UTIs agents ${ }^{7}$. Antibiotics used for bacterial infection management are usually empirical in some areas in developing world. This can lead to bacterial resistance among pathogens.

Antibiotic-resistant microorganisms pose serious threats to both mother and foetus as treatment becomes more difficult with safe antibiotics. The development of anti-microbial resistance in many bacterial species constitutes one of the most serious problems in the control of infectious diseases. Constant exposure of clinical bacterial isolates to hospital environment and exchange of genetic material among different species, results to acquisition of resistance to numerous antibiotics by various mechanisms ${ }^{1}$.

UTIs cause high morbidity rates, high financial cost in communities and are the most common bacterial infections ${ }^{8}$. The immune system of pregnant women is reduced during pregnancy, predisposing them to bacterial infections. The study of immunological parameters, uro-pathogenic bacteria and resistance is necessary to guide the clinicians for the proper management and prevention of UTIs in pregnant women. Therefore, this study is designed to determine the bacterial profile, antibiotic resistant pattern of uro-pathogens and immunological profile among pregnant and non-pregnant women consulting at the Mbouda Ad-Lucem hospital, Western Region of Cameroon. This is to update our knowledge on the area-based prevalence and antibiotic resistant pattern for antibiotics used for the proper management and prevention of UTIs during pregnancy.

\section{Methodology \\ Study design and area}

A cross-sectional study was conducted from December 2015 to May 2016 at the Mbouda Ad-Lucem hospital, located about $700 \mathrm{~m}$ from the Mbouda center. Mbouda is found in the Bamboutos Division, Western Region of Cameroun. This hospital is one of the reference Centres in Bamboutos Division.

\section{Ethics approvals}

The study was approved by the Ethics Review and Consultancy Committee of the Cameroon Bioethics Initiative (CAMBIN). After obtaining an informed written consent, socio-demographic and clinical data were obtained from each participant. All data obtained in the course of the study were kept confidential and used exclusively for the purpose of the study. The laboratory analysis results of participants in this study were communicated to the clinicians assigned and responsible for ante-natal visit and management at the Mbouda Ad-Lucem hospital for proper treatment.

\section{Study participants}

104 asymptomatic pregnant women attending ante-natal visit and 24 symptomatic non-pregnant women coming for UTIs consultation during the study period were enrolled in the study. All socio-demographic and clinical data were taken after obtaining an informed written consent from each participant. Participants treated with antibiotics within the preceding 2 weeks, known anatomic and neurologic urinary tract abnormalities, diabetic, HIV-pregnant women were excluded from the study. 


\section{Sample collection}

Clean-catch mid-stream urine samples $(6-12 \mathrm{ml})$ were obtained from each participant in a sterile screw-capped wide-mouth container after informing them about proper urine collection method. The containers were labelled with a unique sample number, date and time of collection. The urine samples were processed within an hour after collection in the bacteriological laboratory of Mbouda Ad-Lucem hospital.

\section{Culture and identification of bacterial species}

Urine samples were directly inoculated in a prepared nutrient broth and incubated for $24 \mathrm{~h}$ at $37^{\circ} \mathrm{C}$. Loopful of the inoculated nutrient broth were then cultured by successive streaking on Cystine Lactose Electrolyte Deficient (CLED) agar (Qarad b.v.b.a. (Geel), Belgium), Chapman agar or Mannitol Salt Agar (MSA) (Qarad b.v.b.a. (Geel), Belgium), Eosin Methylene Blue (EMB) Agar (Qarad b.v.b.a. (Geel), Belgium) for the detection of E. coli, Klebsiella sp., Staphylococcus sp., Staphylococcus aureus, Gardnerrella vaginalis, Serratia sp., Aeromonas hydrophilai, Proteus sp.. CLED medium is mostly used in hospital laboratories for the diagnosis of urinary bacterial because it supports the growth of both Gram-positive and Gram-negative urinarypotential pathogens. Nevertheless, it is not possible to differentiate between E. coli and S. aureus. EMB and MSA are also selective media and they can clearly differentiate gram positive from gram negative bacteria. The bacterial isolates were further characterized using standard microbiology techniques such as colony morphology, Gram-staining, catalase test and other biochemical tests which include oxidase, indole, citrate utilization, H2S production, Voges-Proskauer, methyl red, urease and sugar fermentation testes?.

\section{Susceptibility testing}

Antibiotics susceptibility test was performed using Kirby-Bauer disc diffusion method ${ }^{10}$. Bacterial suspensions were prepared using nutrient broth by peaking-up 2-4 colonies from pure culture and adjusting it to $0.5 \mathrm{Mc}-\mathrm{Far}-$ land standard which is equal to $10^{8}$ cells $/ \mathrm{mL}$. It was then inoculated by swabbing onto Mueller-Hinton Agar (Qarad b.v.b.a. (Geel), Belgium). Antibiotic impregnated discs were placed on the surface of culture medium using a sterile gip. The isolates were tested with Tetracycline (30 ug) (TET), Cephalothin (30 ug) (CEP), Ciprofloxacin (30 ug) (CIP), Streptomycin (10 ug) (STR), Norfloxacin(10 ug) (NOR), Chloramphenicol (30 ug) (CHL), Gentamicin (15 ug) (GEN), Amoxicillin (30 ug) (AMO), Doxycycline (30 ug) (DOX), Netilmicin (30 ug) (NET), and Amoxicillin/Clavulanic acid ((20/10) ug ) (AMC), Verna Industrial Estate, Verna Goa, India). After 24 hours of incubation at $37^{\circ} \mathrm{C}$, zones of growth inhibition were measured to the nearest whole millimetre using a calliper. The zones of inhibition were interpreted according to the Clinical and Laboratory Standards Institute (CLSI) guideline as susceptible (S), intermediate (I) or resistant $(\mathrm{R})^{11}$. Multidrug resistance (MDR) was defined as the resistance of a bacterium to at least threefamilies of antibiotics ${ }^{12}$.

\section{Blood Count, CD4, CD8 count and C-reactive pro- tein dosage}

Blood was collected in labelled EDTA (Ethylenediaminetetraacetic Acid) tubes and were gently agitated to avoid the formation of clots. Each tube was then introduced into an automated analyzer (Hemascreen 18; Hospitex diagnosis; Firenze, Italie). After 9 seconds, the automat analyzed and posted the concentrations of: white blood cells, lymphocytes, monocytes and granulocytes.

The CD4 and CD8 T-lymphocytes count of all participants was determined using flow Cytometry applied in clinical immunology by the Becton Dickinsons' FACS count method $^{13}$. The dosage of C-reactive protein (CRP) was done by immune-turbidimetry technique ${ }^{14}$.

\section{Data analysis}

Descriptive statistics were computed and summarised; continuous variables were expressed as means and standard deviations (SD) while categorical variables were expressed as proportions. Significance of differences between pregnant and non-pregnant women means variables were assessed using Student's t-test while chisquared Statistic was employed to determine the proportions of significance resultsbetween groups. The level of statistical significance was set at $\mathrm{p}<0.05$.

\section{Results}

A total of 128 urine specimens were received from the Mbouda Ad-Lucem Hospital with pregnant women $(\mathrm{n}=104)$ and non-pregnant women $(\mathrm{n}=24)$ (Supplementary Material Table S1 and S2). Bacteriuria was found in 
$38 \%$ of the pregnant women and in $75 \%$ of the non-pregnant women. $47.5 \%(\mathrm{n}=19)$ of pregnant and $55.55 \%$ $(n=10)$ of non-pregnant women were aged 30 years and above. No significant difference was observed between ages in pregnancy status, with a Chi-square goodness of fit $\chi^{2}=0.326, \mathrm{p}=0.849$ (Table 1$)$. Table 1 also shows that, pregnant women had a significantly high granulocytes $(p=0.009)$ and monocytes $(P=0.001)$ average, high ratio of $\mathrm{CD} 4 / \mathrm{CD} 8(\mathrm{p}<0.0001)$ and significantly low CD8 lymphocytes $(p<0.0001)$ average compared to non-pregnant women.

Table 1. Demographic and clinical characteristics by pregnancy status

\begin{tabular}{llll}
\hline Sample characteristic & $\begin{array}{l}\text { Pregnant women } \\
\mathrm{n} \text { (frequency) }\end{array}$ & $\begin{array}{l}\text { Non pregnant women } \\
\mathrm{n} \text { (frequency) }\end{array}$ & \\
\hline Age group (years) & & & Chi-square \\
$<20$ & $5(12.5 \%)$ & $2(11.11 \%)$ & $0.326(0.849)$ \\
$20-30$ & $16(40 \%)$ & $6(33.33 \%)$ & \\
$>30$ & $19(47.5 \%)$ & $10(55.55 \%)$ & \\
\hline
\end{tabular}

\begin{tabular}{llll} 
Blood parameters & Mean \pm standart deviation & Mean \pm standart deviation & $\begin{array}{l}\text { Probabilities } \\
\text { (p-value) }\end{array}$ \\
\hline Leucocytes & $6.895 \pm 0.453$ & $6.80 \pm 0.744$ & 0.904 \\
Lymphocytes & $1.644 \pm 0.600$ & $1.588 \pm 0.142$ & 0.948 \\
Granulocytes & $4.130 \pm 0.310$ & $3.66 \pm 0.61$ & $\mathbf{0 . 0 0 9}$ \\
Monocytes & $1.117 \pm 0.197$ & $1.523 \pm 0.42$ & $\mathbf{0 . 0 0 1}$ \\
CD4 & $724.2 \pm 34.9$ & $749.11 \pm 60.75$ & 0.506 \\
CD8 & $458.5 \pm 31.1$ & $549.1 \pm 33.1$ & $<\mathbf{0 . 0 0 0 1}$ \\
CD4/CD8 & $1.781 \pm 0.112$ & $1.446 \pm 0.147$ & $<\mathbf{0 . 0 0 0 1}$ \\
\hline
\end{tabular}

n: number

Bacteriuria was observed in 18/24 (75\%) non-pregnant and 40/104 (38\%) pregnant women (figure 1). Gram-positive bacteria were the most prevalent UT pathogen in both pregnant $60 \%(n=24)$ and non-pregnant $55.55 \%$ $(n=10)$ women than Gram-negative bacteria $40 \%(n=16)$ and $44.44 \%(n=8)$ respectively (figure 1$)$. Of the 40 UT pathogens isolates detected in pregnant women, Staphylo- coccus sp. 45\% ( $\mathrm{n}=18)$, Staphylococcus aureus $15 \%(\mathrm{n}=6)$ and Escherichia coli $12.5 \%(\mathrm{n}=5)$ were the most common isolated bacteria of the UT flora. Interestingly, non-pregnant women, harboured Staphylococcus sp. 38.89\% (n=7), Gardnerrella vaginalis $16.67 \%(\mathrm{n}=3)$, Staphylococcus aureus $16.67 \%$ $(\mathrm{n}=3)$ and Escherichia coli $11.11 \%(\mathrm{n}=2)$ as the most prevalent isolated UT bacteria (figure 1). 


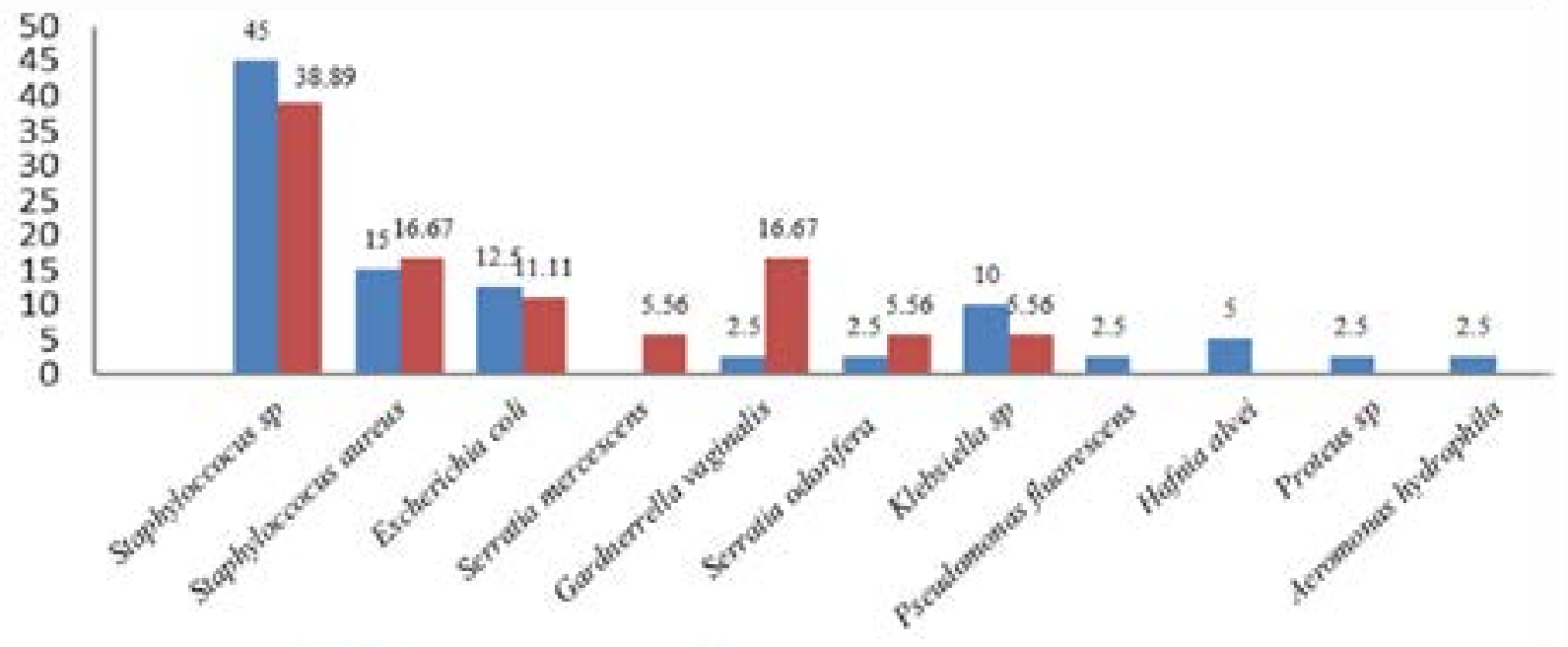

Pregnant women $\quad$ Non pregnant women

\section{Figure 1. Distribution of bacterial isolates in relation to pregnancy status}

Uro-pathogenics bacterial isolates from UT infected patients revealed high levels of single antibiotics resistances toward commonly prescribed drugs (Table 2). Resistance of Staphylococcus sp. to AMO ( $\mathrm{P}=0.013)$ was significantly higher in pregnant women than in non-pregnant women. Resistance of Staphylococcus sp. to CHL ( $\mathrm{P}=0.047$ ) was significantly higher in non-pregnant women than in pregnant women. Resistance of Escherichia coli to AMO $(\mathrm{P}<0.0001)$, CEP $(\mathrm{P}<0.0001)$, GEN $(\mathrm{P}=0.022)$ and to $\operatorname{NOR}(\mathrm{P}=0.001)$ was significantly higher in pregnant women than in non-pregnant women, contrary to TET $(\mathrm{P}=0.022)$, DOX $(\mathrm{P}=0.022)$. Resistance of Staphyloccocus aureus to DOX $(\mathrm{P}=0.030)$ was significantly higher in pregnant women than in non-pregnant women. Serratia oderifera showed highly significant resistance to CEP ( $\mathrm{P}<0.0001)$, STR ( $<0.0001)$, CHL ( $<<0.0001)$ in non-pregnant women than in pregnant women contrary to $\operatorname{DOX}(\mathrm{P}<0.0001)$ (Table 2). 
Table 2. Distribution of bacteria resistance among pregnant and non-pregnant women

\begin{tabular}{|c|c|c|c|c|c|c|c|c|c|c|c|}
\hline \multirow[b]{2}{*}{ Bacteria } & \multirow[b]{2}{*}{ Number of isolate } & \multicolumn{10}{|c|}{ Antibiotics (Number (\%)) } \\
\hline & & AMO & AMC & CEP & GEN & STR & NOR & CIP & $\mathrm{CHL}$ & TET & DOX \\
\hline Staphyloccocus sp* & 18 & $10(55.56)$ & $13(72.22)$ & $6(33.33)$ & $5(83.33)$ & $6(33.33)$ & $12(66.67)$ & $6(33.33)$ & $14(77.78)$ & $16(88.89)$ & $12(66.67)$ \\
\hline Staphyloccocus sp ii & 7 & 1(14.29) & $5(71.43)$ & 1(14.29) & $2(28.57)$ & $4(57.41)$ & $6(85.71)$ & $4(57.41)$ & $7(100)$ & $7(100)$ & $6(85.71)$ \\
\hline$p$-value & & 0.013 & 0.859 & 0.206 & 0.921 & 0.334 & 0.346 & 0.334 & 0.047 & 0.261 & 0.346 \\
\hline Staphyloccocus aureus* & 6 & $4(66.67)$ & $4(66.67)$ & $0(00)$ & $1(16.67)$ & $1(16.67)$ & $0(00)$ & $1(16.67)$ & $0(00)$ & $2(33.33)$ & $2(33.33)$ \\
\hline Staphyloccocus aureus & & & & & & & & & & & \\
\hline$* *$ & 3 & $1(33.33)$ & $1(33.33)$ & $0(00)$ & $1(33.33)$ & $0(00)$ & $0(00)$ & $0(00)$ & $0(00)$ & $1(33.33)$ & $0(00)$ \\
\hline p-value & & 0.211 & 0.211 & 1.000 & 0.789 & 0.100 & 1.000 & 0.100 & 1.000 & 0.803 & 0.030 \\
\hline Escherichia coli* & 5 & $4(80)$ & $5(100)$ & $4(80)$ & $2(40)$ & $2(40)$ & $3(60)$ & $1(20)$ & $0(00)$ & $2(40)$ & $2(40)$ \\
\hline Escherichia coli** & 2 & $0(00)$ & $1(50)$ & $0(00)$ & $0(00)$ & $1(50)$ & $0(00)$ & $0(00)$ & $0(00)$ & $2(100)$ & $2(100)$ \\
\hline$p$-value & & $<0.0001$ & 0.090 & $<0.0001$ & 0.022 & 1.000 & 0.001 & 0.094 & 1.000 & 0.022 & 0.022 \\
\hline Serratia mercescens* & 0 & $0(00)$ & $0(00)$ & $0(00)$ & $0(00)$ & $0(00)$ & $0(00)$ & $0(00)$ & $0(00)$ & $0(00)$ & $0(00)$ \\
\hline $\begin{array}{l}\text { Serratia mercescens** } \\
\text { p-value }\end{array}$ & 1 & $1(100)$ & $1(100)$ & $1(100)$ & $1(100)$ & $1(100)$ & $1(100)$ & $1(100)$ & $0(00)$ & $1(100)$ & $1(100)$ \\
\hline $\begin{array}{l}\text { Gardnerrella vaginalis* } \\
\text { Gardnerrella }\end{array}$ & 1 & $1(100)$ & $1(100)$ & $1(100)$ & $1(100)$ & $1(100)$ & $1(100)$ & $0(00)$ & $1(100)$ & $1(100)$ & $1(100)$ \\
\hline vaginalis** & 3 & $3(100)$ & $3(100)$ & $3(100)$ & $3(100)$ & $3(100)$ & $3(100)$ & $1(33.33)$ & $3(100)$ & $3(100)$ & $3(100)$ \\
\hline$p$-value & & 1.000 & 1.000 & 1.000 & 1.000 & 1.000 & 1.000 & 0.540 & 1.000 & 1.000 & 1.000 \\
\hline Serratia oderiferal * & 1 & $1(100)$ & $1(100)$ & $0(00)$ & $1(100)$ & $0(00)$ & $1(100)$ & $0(00)$ & $0(00)$ & $1(100)$ & $1(100)$ \\
\hline Serratia oderiferal** & 1 & $1(100)$ & $1(100)$ & $1(100)$ & $1(100)$ & $1(100)$ & $1(100)$ & $0(00)$ & $1(100)$ & $1(100)$ & $0(00)$ \\
\hline$p$-value & & 1.000 & 1.000 & $<0.0001$ & 1.000 & $<0.0001$ & 1.000 & & $<0.0001$ & 1.000 & $<0.0001$ \\
\hline $\begin{array}{l}\text { Pseudomonas } \\
\text { fluorescens* }\end{array}$ & 1 & $0(00)$ & $0(00)$ & $0(00)$ & $0(00)$ & $0(00)$ & $0(00)$ & $0(00)$ & $0(00)$ & $0(00)$ & $0(00)$ \\
\hline $\begin{array}{l}\text { Pseudomonas } \\
\text { fluorescens** }\end{array}$ & 0 & $0(00)$ & $0(00)$ & $0(00)$ & $0(00)$ & $0(00)$ & $0(00)$ & $0(00)$ & $0(00)$ & $0(00)$ & $0(00)$ \\
\hline $\begin{array}{l}\text { p-value } \\
\text { Hafniaalve* }\end{array}$ & 2 & $2(100)$ & $2(100)$ & $1(50)$ & $2(100)$ & $1(50)$ & $2(100)$ & $1(50)$ & $2(100)$ & $2(100)$ & $2(100)$ \\
\hline Hafniaalvei** & 0 & $0(00)$ & $0(00)$ & $0(00)$ & $0(00)$ & $0(00)$ & $0(00)$ & $0(00)$ & $0(00)$ & $0(00)$ & $0(00)$ \\
\hline p-value & & & & & & & & & & & \\
\hline Proteus $s p^{*}$ & 1 & $1(100)$ & $1(100)$ & $1(100)$ & $1(100)$ & $0(00)$ & $1(100)$ & $1(100)$ & $0(00)$ & $1(100)$ & $1(100)$ \\
\hline Proteus sp ii & 0 & $0(00)$ & $0(00)$ & $0(00)$ & $0(00)$ & $0(00)$ & $0(00)$ & $0(00)$ & $0(00)$ & $0(00)$ & $0(00)$ \\
\hline -value & & & & & & & & & & & \\
\hline Aeromonas hydrophila* & 1 & $1(100)$ & $1(100)$ & $1(100)$ & $1(100)$ & $1(100)$ & $1(100)$ & $0(00)$ & $1(100)$ & $1(100)$ & $1(100)$ \\
\hline $\begin{array}{l}\text { Aeromonas } \\
\text { hydrophila** } \\
\text { p-value }\end{array}$ & 0 & $0(00)$ & $0(00)$ & $0(00)$ & $0(00)$ & $0(00)$ & $0(00)$ & $0(00)$ & $0(00)$ & $0(00)$ & $0(00)$ \\
\hline Klebsiella $p^{*}$ & 4 & $3(75)$ & $4(100)$ & $3(75)$ & $3(75)$ & $3(75)$ & $3(75)$ & $3(75)$ & $2(50)$ & $4(100)$ & $4(100)$ \\
\hline Klebsiella $s p^{* *}$ & 1 & $1(100)$ & $1(100)$ & $1(100)$ & $1(100)$ & $1(100)$ & $0(00)$ & $0(00)$ & $1(100)$ & $1(100)$ & $1(100)$ \\
\hline$p$-value & & 0.564 & 1.000 & 0.564 & 0.564 & 0.564 & $<0.0001$ & $<0.0001$ & 0.134 & 1.000 & 1.000 \\
\hline
\end{tabular}

Uro-pathogenic isolates from UT infected pregnant and non-pregnant women revealed the presence of high levels of multiple antimicrobial resistances against commonly prescribed drugs (Table 3). Multidrug-resistance of Escherichia coli to Quinolones (NOR, CIP) was significantly higher in pregnant women compared to non-pregnant women $(\mathrm{P}=0.018)$. The Escherichia coli isolates were significantly multidrug-resistance in pregnant women than in non-pregnant women $(\mathrm{P}=0.018$ ) (Table 3). Klebsiella $s p$. were only isolated in pregnant women and were more resistant to beta-lactamine (AMO, AMC, and CEP), aminosides (GEN, NET, and STR) and cycline (TET, DOX). The White Blood cells (WBC) involved in the defence of an organism, particularly the lymphocytes, monocytes and granulocytes, were counted. Table 4 compares the principal abnormalities of the WBCs observed among pregnant and non-pregnant women. It could be observed that the pregnant women had a significantly and highly pronounced lymphocytosis and monocytosis than non-pregnant women (Table 4). 
Table 3. Bacteria resistance and multidrug resistance among pregnant and non-pregnant women

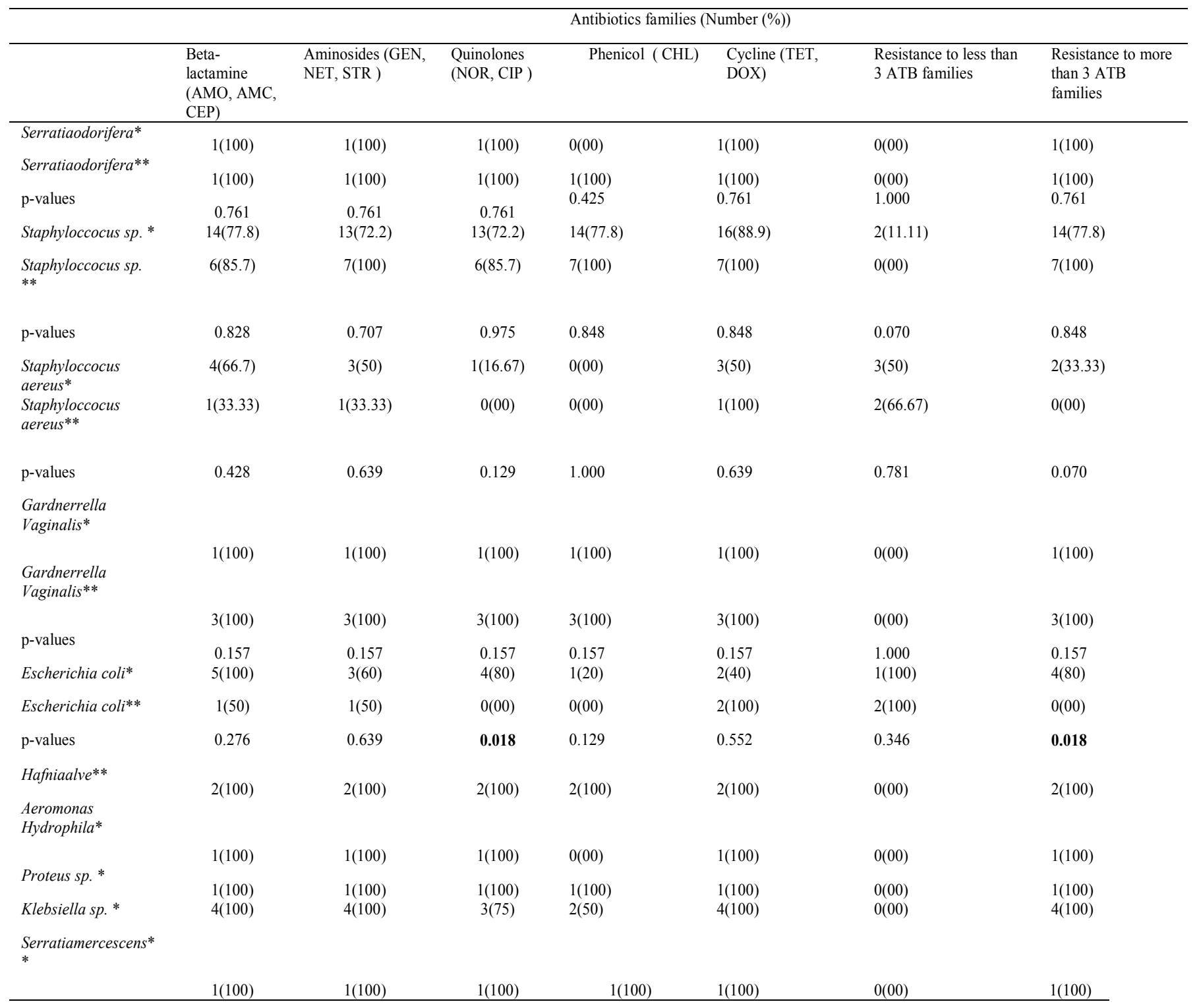

*: pregnant women, **: non-pregnant women, TET: Tetracycline, CEP: Cephalothin, CIP: Ciprofloxacin, STR: Streptomycin, NOR: Norfloxacin, CHL: Chloramphenicol, GEN: Gentamicin, AMO: Amoxicillin, DOX: Doxycycline, AMC: Amoxicillin/Clavulanic acid. 
Table 4. Principal abnormalities of white blood cells among pregnant and non-pregnant women

\begin{tabular}{|c|c|c|c|c|c|}
\hline \multirow[b]{2}{*}{$\begin{array}{l}\text { Principal } \\
\text { anormalities }\end{array}$} & \multicolumn{2}{|c|}{ Pregnant women $(n=40)$} & \multicolumn{3}{|c|}{ Non pregnant women $(\mathrm{n}=18)$} \\
\hline & frequency & Percentage $(\%)$ & frequency & Percentage $(\%)$ & $\begin{array}{l}\text { P-value } \\
\end{array}$ \\
\hline Leucopenia & 3 & 7.5 & 3 & 16.67 & 0.415 \\
\hline Granulopenia & 3 & 7.5 & 5 & 27.78 & $\begin{array}{l}0.094 \\
0.212\end{array}$ \\
\hline Lymphopenia & 22 & 55.0 & 7 & 38.89 & \\
\hline Monopenia & 1 & 2.5 & 1 & 5.56 & 0.101 \\
\hline Leucocytosis & 5 & 12.5 & 4 & 22.22 & \\
\hline Granulocytosis & 2 & 5.0 & 3 & 16.67 & $0.2 / 0$ \\
\hline Lymphocytosis & 3 & 7.5 & 0 & 00.00 & 0.036 \\
\hline $\begin{array}{l}\text { monocytosis } \\
\text { CRP }\end{array}$ & 13 & 32.5 & 11 & 61.11 & $\begin{array}{l}0.045 \\
\text { Chi-square (p-value) }\end{array}$ \\
\hline$\leq 6$ & 13 & 32.5 & 4 & 22.22 & $0.771(0.680)$ \\
\hline $6<\mathrm{CRP}<40$ & 10 & 25.0 & 6 & 33.33 & \\
\hline$>40$ & 17 & 42.5 & 8 & 44.44 & Chi-square (n-value) \\
\hline$<500$ & 8 & 20.0 & 3 & 16.67 & $0.090(0.764)$ \\
\hline$>500$ & 32 & 80.0 & 15 & 83.33 & \\
\hline CD8 $>200$ & 40 & 100.0 & 18 & 100.00 & Chi-square (n-value) \\
\hline CD4/CD8 & 4 & 10.0 & 4 & 22.22 & $1.560(0.121)$ \\
\hline$>1$ & 36 & 90.0 & 14 & 77.78 & \\
\hline
\end{tabular}

\section{Discussion}

Bacteriuria in pregnant women is an important causative factor of premature birth, low birth weight, postpartum UTIs and higher foetal mortality rates. Women with bacteriuria have a $20-50$-fold increased risk of developing pyelonephritis compared to women who do not have bacteriuria ${ }^{15}$. In this study, the prevalence of bacteriuria was 38\% in pregnant women and $75 \%$ in non-pregnant women. The high incidence of UTI in non-pregnant women $(75 \%)$ is as a result of their symptomatic status when they were included in this study. Low incidence of bacteriuria $(38 \%)$ in pregnant women can be a result of their asymptomatic status and regular ante-natal visits when they were included in this study.

In this study, a highly significant average value of Monocytes $(p=0.001)$ and granulocytes $(p=0.009)$, high ratio of CD4/CD8 $(\mathrm{p}<0.0001)$ and significantly low CD8 lymphocytes average value in pregnant women compared to non-pregnant women was reported. A highly significant average value of Monocytes and granulocytes is due to pregnancy ${ }^{16}$. Pregnancy is associated with leukocytosis, primarily related to increased circulation of neutrophils. The neutrophil gradually increase as from weeks 6-8 of pregnancy and a plateau attained in the second or third trimester ${ }^{16}$. In healthy women with normal pregnancies, there is no change in the absolute lymphocyte count and no significant changes in the relative numbers of lymphocytes $^{17}$.

Pregnancy is associated to some physiological and hormonal changes. At the first and second semester of pregnancy, the ureter begins to dilate and it continues until delivery. Increased progesterone and oestrogens levels normally leads to decrease ureteral and bladder tone. Increased plasma volume during pregnancy leads to decrease urine concentration and increase bladder volume. The combination of these factors leads to urinary stasis and uretero-vesical reflux ${ }^{18}$. These changes during pregnancy makes it easier for bacteria to travel up the urethra, kidney and causes development of bacteriuria.

Gram-positive bacteria were more prevalent in pregnant women 60\% ( $\mathrm{n}=24)$ (Staphylococcus sp. 45\% $(\mathrm{n}=18)$, Staphylococcus aureus $15 \%(\mathrm{n}=6))$ and non-pregnant women 
55.55\% ( $\mathrm{n}=10)$ (Staphylococcus sp. 38.89\% ( $\mathrm{n}=7)$, Staphylococcus aureus $16.67 \%(\mathrm{n}=3)$ ) than Gram-negative bacteria $40 \%(\mathrm{n}=16)$ and $44.44 \%(\mathrm{n}=8)$ bacteria in pregnant and non-pregnant women with bacteriuria. These bacteria are those of the digestive flora that often colonizes the maternal genital tract. These varying results may have been due to differences in the areas being studied, in the social habits of the communities being studied, standards of personal hygiene and levels of education of the participants being studied since these factors can influence the spread and bacterial multiplication.

The most commonly isolated bacteria in pregnant women were Staphylococcus sp. 45\% ( $\mathrm{n}=18)$, Staphylococcus aureus 15\% $(\mathrm{n}=6)$, Escherichia coli $12.5 \%(\mathrm{n}=5)$ and Klebsiella sp. $10 \%(\mathrm{n}=4)$. In non-pregnant women, the most commonly isolated bacteria were Staphylococcus sp. 38.89\% ( $\mathrm{n}=7$ ), Gardnerrella vaginalis $16.67 \%(\mathrm{n}=3)$, Staphylococcus aureus $16.67 \%(\mathrm{n}=3)$ and Eschericbia coli $11.11 \%(\mathrm{n}=2)$. This finding is consistent with a study conducted by Oko et al. ${ }^{19}$ who showed that Staphylococcus aureus was the most prevalent uropathogen $(29 \%)$ in pregnant women attending a tertiary maternity clinic in Northern Nigeria. Amadi et al. ${ }^{20}$ reported $27.1 \%$ and $25.4 \%$ for Staphylococcus aureus and Eschericbia coli respectively. However, this observation differs from that of Akoachere et al..$^{21}$ in Bamenda-Cameroon who reported that Klebsiella oxytoca was the most prevalent organism. Variation in geographical location can account for these differences.

This study has, thus, revealed that bacterial agents were significantly associated with increase resistance to antibiotics, such as AMO (55.56\%) by Staphylococcus sp., DOX $(33.33 \%)$ by Staphylococcus aureus, AMO (80\%), CEP (80\%), GEN (40\%), and NOR (60\%) by Escherichia coli, and NOR $(75 \%)$, CIP $(75 \%)$ by Klebsiella sp. in pregnant women. In non-pregnant women, bacteria resistance was exhibited for; CEP (100\%), STR (100\%), CHL (100\%), by Serratia oderifera, TET (100\%), DOX (100\%), by Escherichia coli, CHL (100\%), by Staphylococcus sp.

The resistance to usually prescribed antibiotics observed in our study can be due to frequent exposure to antibiotics in the locality.It is worth noting that the administration of cephalosporins (CEP) is relatively safer during pregnancy as compared to quinolones (CIP, NOR...) which are contra-indicated unless there are no other alternatives ${ }^{22}$. Resistance of Escherichia coli to quinolones (NOR, CIP) was significantly high in pregnant women compared to non-pregnant women $(\mathrm{P}=0.018)$. The Eschericbia coli isolates were significantly MDR in pregnant women compared to non-pregnant women $(\mathrm{P}=0.018)$. Klebsiella sp. were only isolated in pregnant women and were more resistant to beta-lactamine (AMO, AMC, CEP), aminosides (GEN, NET, STR) and cyclines (TET, DOX). This may be as a result of the high use of antibiotics by the pregnant women or the bacteria immunity that causes the destruction of any substances that does not allow their growth.

Lymphocytosis and monocytosis were more pronounced in pregnant women than non-pregnant women. This may be as a result of the body building immunity of the foetus and it is achieved by a state of selective immune tolerance, immunosuppression, and immunomodulation in the presence of a strong antimicrobial immunity ${ }^{23}$. There is also down regulation of potentially dangerous T-cell-mediated immune responses while activating certain components of the innate immune system, such as neutrophils. This unique deregulation between different components of the immune system plays a central role in the maternal adaptation to pregnancy ${ }^{23}$.

The limitation of this study may be the representation of this findings in the entire pregnant and non-pregnant women population in the studied area; however, the results could be of interest to physicians and other health professionals in Cameroon and worldwide who should apply the findings of this study according to the methodology and especially after comparing the context of the study with their own situation. Further studies will be performed to increase the reliability of these findings.

\section{Conclusion}

Urinary tract infection is caused by bacterial colonization of the urethra and the most prevalent agents of urinary tract infection found in this study were Staphylococcus sp. $45 \%$, Staphylococcus aureus 15\%, Escherichia coli $12.5 \%$ in pregnant women while in non-pregnant women, the most commonly isolated bacteria were Staphylococcus sp. $38.89 \%$, Gardnerrella vaginalis $16.67 \%$, Stapbylococcus aureus $16.67 \%$ and Eschericbia coli $11.11 \%$. Lymphocytosis and 
monocytosis are more pronounced in pregnant women than non-pregnant women, the prevalence of resistance profile of uropathogens to some antibiotics tested in this study are a serious call for concern. Routine urine culture and antibiotic susceptibility testing and white blood cells count are recommended in pregnancy to identify bacterial causes of urinary tract infections and normal pregnancy for prompt attention and treatment to avoid complications.

\section{Funding}

No funding sources.

\section{Ethical approval}

Ethical clearance for this study was obtained from the Ethics Review and Consultancy Committee of the Cameroon Bioethics Initiative (CAMBIN). All authors hereby declare that all experiments have been examined and approved by the appropriate ethical committee and have therefore been performed in accordance with the ethical standards laid down in the 1964 Declaration of Helsinki.

\section{Competing interests}

Authors have declared that no competing interests exist.

\section{Authors' contributions}

JWTM and VK designed the study. LMN carried out sample and data collection. JWTM, and VK participated in analysis of the samples, data management and statistics. JWTM, and VK drafted the manuscript. All authors read the manuscript and approved the final version prior to submission.

\section{Abbreviations}

AMC: Amoxicillin/Clavulanic acid; AMO: Amoxicillin; CAMBIN: Cameroon Bioethics Initiative; CD: Cluster of Differentiation; CEP: Cephalothin; CHL: Chloramphenicol; CIP: Ciprofloxacin; CLED: Cystine Lactose Electrolyte Deficient; CLSI: Clinical and Laboratory Standards Institute; CRP: C-reactive protein; DOX: Doxycycline; EMB: Eosin Methylene Blue; GEN: Gentamicin; MSA: Chapman agar or Mannitol Salt Agar; NOR: Norfloxacin; STR: Streptomycin; TET: Tetracycline; UT: Urinary Tract; UTIs: Urinary Tract infections, HIV: Human Immunodeficiency Virus; EDTA: Ethylenediaminetetraacetic Acid

\section{Acknowledgments}

The authors would like to acknowledge the participation of all pregnant and non-pregnant women enrolled in this study and all the staff of Mbouda Ad-Lucem hospital-Cameroon.

\section{References}

1. Anyadoh S, Akerele J, Udum U. Prevalence of multidrug resistant Escherichia coli among pregnant Women in Owerri. International Journal of Medical Sciences and Technology, India. 2010, 3(3):17-20

2. Onuh S, Umeora O, Igberase G, Azikem M, Okpere E. Microbiological Isolates and sensitivity pattern of urinary tract infection in pregnancy in Benin City, Nigeria. Ebonyi Medical Journal. 2006, 5(2):48 -52.

3. Akerele, J, Okonofua F. (2002). Prevalence of asymptomatic genital infection among pregnant women in Benin-city, Nigeria. African Journal of Reproductive Health; 6(3) 93-97.

4. Le J, Briggs G, McKeown A, Bustillos G. Urinary System Infections During Pregnancy. Annals of Pharmacotherapy. 2004, 38:1692-1701.

5. Gilstrap L, Ramin S: Urinary Tract Infections during Pregnancy. Obstetrics and Gynecology Clinics of North America. 2001, 28(3):581 -591.

6. Anyadoh-Nwadike O, Okorondu I, Obiajuru O, Nwadike O, Nwaokorie F, Akerele O. Comparative Study of the Prevalence and Antibiogram of Bacterial Isolates from the Urinary and Genital Tracts of Antenatal Patients. Journal of Pharmacy and Biological Sciences. 2015, 10(1):15-19.

7. Loh K, Sivalingam N. Urinary tract infectionsin pregnancy. Malaysian Fam Physician. 2007, 2:54-57.

8. Devan P, Ramchandra S. Distribution and antimicrobial susceptible pattern of bacterial pathogens causing urinary tract infection in Urban community of Meerut city India . ISRN Microbiology. 2013, 2013.

9. Cheesbrough M. Medical Laboratory Manual for Tropical Countries. 2nd Edition, In. South Africa: Cambrige University Press; 2006.

10. Bauer A, Kirby W, Sherris J, Turck M. Antibiotic suscep-tibility testing by standard single disc method. Am J Clin Pathol. 1966, 45:493-496.

11. CLSI. Performance Standards for Antimicrobial Susceptibility Testing; Twenty-Fourth Informational Supplement, M100-S24, 228. In.; 2014.

12. Martinez J. The role of natural environments in the evolution of resistance traits in pathogenic bacteria. Proc Biol Sci. 2009, 276 (1667):2521-2530.

13. Brando B, Barnett D, Janossy G, Mandy F, Autran B, 
Rothe G, Scarpati B, D'Avanzo G, D'Hautcourt J, R RL et al. Cytofluorometric methods for assessing absolute numbers of cell subsets in blood. European Working Group on Clinical Cell Analysis Cytometry. 2000, 42 327-346.

14. Otsuji S, Shibata H, Umeda M. Turbidimetric immunoassay of serum C-reactive protein. Clin Chem. 1982, 28:2121-2124

15. Celen AO, Karayalcin R:. Asymptomatic bacteriuria and antibacterial susceptibility patterns in an obstetric population. ISRN Obstetric Gynaecology Idealistic Studies. 2011, 72(1):872.

16. Kuvin S, Brecher G. Differential neutrophil counts in pregnancy. N Engl Journal Medical. 1962, 266:87-88.

17. Kuhnert M, Strohmeier R, Stegmuller M, Halberstadt E. Changes in lymphocyte subsets during normal pregnancy. European Journal of Obstetrics Gynecology Reproductive Biology. 1998, 76:147-151

18. Dezell J, Lefevre M. Urinary tract infections during pregnancy. American Family Pbysician. 2000, 61(3):713-721.
19. Oko J, Abriba C, Umar M, Asitok AD, Audu JA, Jakheng SPE, Ojeleye FS, Amos AK. Antibiotics Susceptibility Study of Uropathogens Isolated from Asymptomatic Pregnant Women Attending a Tertiary Maternity Clinic in Northern Nigeria. Journal of Complementary and Alternative Medical Research. 2017, 2(3):1-9.

20. AmadiE, Enemuo O, Uneke C, Nwosu O, Onyeagba $\mathrm{R}$, Ugbogu O. Asymptomatic bacteriuria among pregnant women in Abakaliki, Ebonyi State Nigeria. J Med Sci. 2007, 7(4):698-700.

21. Akoachere J, Suylika Y, Njom H, Esemu N. Etiological profile and antimicrobial susceptibility of community acquired urinary tract infection in two Cameroon towns. BMC Research Notes. 2012, 5(1):219.

22. Mehlhorn A, Brown D. Safety concerns with fluoroquinolones. Annales Pharmacother. 2007, 41 (11):18591866.

23. Luppi P. How immune mechanisms are affected by pregnancy. H Vaccine. 2003, 21(24):3352-3357. 